\title{
HABITAT UTILIZATION PATTERN OF Lantana camara IN UDAWALAWA NATIONAL PARK
}

\author{
N Gunathillake and DMSHK Ranasinghe \\ Department of Forestry and Environmental Science, \\ University of Sri Jayewardenepura, Nugegoda
}

Time to time, many plant species has been introduced to Sri Lanka either intentionally or accidentally. However, with the present interest on biodiversity it was realized that some of these species are posing a threat to the existence of many other native species. These species are known as invasive species.

Lantana camara an invasive plant is introduced to Sri Lanka in 1926 through the Royal Botanic Gardens of Sri Lanka and current y has spread across the island to a significant extent. Now it has become invasive and a threat to the Udawalawe National Park.

Further more, growth of this species in Udawalawe NP at an alarming rate would eliminate the natural vegetation in this area, rausing loss of habitat for many animal and plant species endangering their survival. To effective manage and control $L$. camara in Udawalawa NP, it is necessary to have knowledge of the distribution within this park and asses the invasive behaviour of this species.

Main objectives of this research study were to find the extent and distribution. This study was conducted in purposely-selected vegetation types such as degraded open secondary forest, scrub grasslands, medium high scrub vegetation, scrub forest transitional vegetation and teak plantation. The percentage coverage was assessed using $2 \mathrm{~m} \times 2 \mathrm{~m}$ quadrats. In each quadrate $\%$ cover of reproductives and non-re rroductives of $L$. camara were measured. Seed samples were germinated in the lab using soil collected from the natural habitat. The study had shown that within the Udawalawa NP, the $L$. ccmara cover affects some vegetation types such as degraded open secondary forest, scrub grass lands, medium high scrub vegetation, scrub forest transitional vegetation and teak plantation. The plant is capable of producing a large number of seeds and it is spreading fast. The seeds shoved high capability of direct germination. Total area of Udawalawa NP is 30821 hectares ar d the area, which consists of $L$. camara, is $20 \%$, spread into above vegetation types covering Udiwalawa NP. The distribution pattern of the species showed that the area around the main road the main road and Veheragolla, Seenuggala, Mauara, Thimbiriyamankada and $5^{\text {th }}$ milepost are the most densely and continuously distributed areas Except this, there are few isolated patches on either side of the road and some vegetation types. It was interesting to note that the density of the $L$. camara is high in open areas than natural forest areas.

As for control methods, uprooting and burning was tested for plants with different cover. Uprooting of small plants was effect ve than mature plants. Mature plants regenerated even from small pieces of rootlets. Cutting drring drought season, showed more effectiveness.

This alien invasive plant, which recluce land productivity and value is a threat specially to this park. Present investigation highligh ts the necessity of proper control method for $L$. camara in Udawalawa NP 